\title{
ARD
}

\section{Blockade of CD40/CD40 ligand interactions attenuates skin fibrosis and autoimmunity in the tight-skin mouse}

K Komura, M Fujimoto, K Yanaba, et al.

Ann Rheum Dis 2008 67: 867-872 originally published online September 6, 2007

doi: 10.1136/ard.2007.073387

Updated information and services can be found at:

http://ard.bmj.com/content/67/6/867.full.html

Topic collections Articles on similar topics can be found in the following collections

Immunology (including allergy) (44341 articles)

Connective tissue disease (7378 articles)

Notes

To order reprints of this article go to:

http://ard.bmj.com/cgi/reprintform

To subscribe to Annals of the Rheumatic Diseases go to:

http://ard.bmj.com/subscriptions 


\title{
Blockade of CD40/CD40 ligand interactions attenuates skin fibrosis and autoimmunity in the tight-skin mouse
}

\author{
K Komura, ${ }^{1,2}$ M Fujimoto, ${ }^{1} \mathrm{~K}$ Yanaba, ${ }^{1} \mathrm{~T}$ Matsushita, ${ }^{1} \mathrm{Y}$ Matsushita, ${ }^{1} \mathrm{M}$ Horikawa, \\ F Ogawa, ${ }^{2}$ K Shimizu, ${ }^{2}$ M Hasegawa, ${ }^{1}$ K Takehara, ${ }^{1}$ S Sato ${ }^{2}$
}

\begin{abstract}
${ }^{1}$ Department of Dermatology, Kanazawa University Graduate School of Medical Science, Kanazawa, Japan; ${ }^{2}$ Department of Dermatology, Nagasaki University Graduate School of Biomedical Sciences, Nagasaki, Japan
\end{abstract}

Correspondence to: Dr Shinichi Sato. Department of Dermatology Nagasaki University Graduate School of Biomedical Sciences. 1-7-1 Sakamoto Nagasaki 852-8501, Japan;

s-sato@net.nagasaki-u.ac.jp

Accepted 26 August 2007 Published Online First 10 September 2007
ABSTRACT

Objective : To assess the association of CD40/CD40 ligand (CD40L) interactions with the development of skin fibrosis and autoimmunity in tight-skin $(\mathrm{TSK} /+)$ mouse, which is a mouse model for human systemic sclerosis. Methods: Newly born TSK/+ mice were treated with murine anti-CD40L monoclonal antibody (100 $\mu \mathrm{g}$ intraperitoneally weekly). Hypodermal thickness of 8-week-old female mice (defined as the thickness of a subcutaneous loose connective tissue layer beneath the panniculus carnosus) was measured under a light microscope. All skin sections were taken from the para-midline, upper back region. Serum anti-topoisomerase I autoantibody levels, serum immunoglobulin levels and plasma soluble CD40L levels were determined by enzyme-linked immunosorbent assay. For analysis of lymphocyte surface molecules, single cell suspensions of lymphocytes were stained by monoclonal antibodies. Proliferation of TSK/+ B cells and fibroblasts to anti-CD40 antibodies was assessed by the uptake of $\left[{ }^{3} \mathrm{H}\right]$-labelled thymidine and bromodeoxyuridine, respectively.

Results: The blockade of CD40/CD40L interactions by anti-CD40L monoclonal antibody significantly reduced cutaneous fibrosis (65\%) and anti-topoisomerase I autoantibody in TSK/+ mice. Anti-CD40L monoclonal antibody also normalised B lymphocyte abnormal activation in TSK/+ mice, demonstrated by hyper- $\gamma$-globulinaemia. Furthermore, augmented CD40/CD40L interactions in TSK/+ mice were suggested by upregulated expression of CD40L on $\mathrm{CD}^{+}{ }^{+} \mathrm{T}$ cells, elevated plasma soluble CD40L levels. The hyperresponsiveness to CD40 stimulation was also observed in TSK/+ B cells and fibroblasts.

Conclusions: Cutaneous fibrosis and autoimmunity in TSK/+ mice are closely correlated with CD40/CD40L interactions.

Systemic sclerosis (SSc) is an autoimmune disease, characterised by connective tissue involvement, with excessive extracellular matrix protein deposition in the skin and other visceral organs. The tight-skin $(\mathrm{TSK} /+)$ mouse is a genetic animal model for human SSc: autoimmune components and cutaneous fibrosis observed in TSK/+ mice resemble those in human SSc. ${ }^{1-4}$ Although a tandem duplication within the fibrillin-1 gene in TSK/+ mice has been suggested to cause the SSclike phenotype, ${ }^{5}$ immune components also contribute to skin fibrosis. Adoptive transfer of both $\mathrm{T}$ and B cells from TSK/+ mice induces cutaneous collagen deposition in wild-type mice. ${ }^{67}$ Deficiency in transforming growth factor- $\beta$, interleukin (IL)- 4 ,
IL-4 receptor, Stat-6, or CD19 as well as the administration of anti-IL-4 antibody, IL-12 or CpG oligodeoxynucleotides prevent or reduce skin fibrosis in TSK/+ mice. ${ }^{8-13}$ Thus, immune components can be a therapeutic approach in TSK/+ mice as well as patients with SSc.

Activated T cells express CD40 ligand (CD40L), which triggers various immune responses, including B cell survival, immunoglobulin class switching, and cytokine production ${ }^{14}$ through CD40/ CD40L interaction. Circulating soluble CD40L (sCD40L) also has biological activities such as cell bounding CD40L. ${ }^{15}$ CD40 is expressed on the surface of immune cells, including B cells, dendritic cells and monocytes/macrophages, ${ }^{14}$ as well as other cell types, such as endothelial cells ${ }^{16}$ and fibroblasts. ${ }^{17} \mathrm{~A}$ therapeutic approach targeting CD40L has been addressed using anti-CD40L monoclonal antibody $(\mathrm{mAb})$. Administration of anti-CD40L mAb, which blocks the biological activity of CD40L/sCD40L, inhibits several animal autoimmune models, such as collagen-induced arthritis and lupus. ${ }^{18} 19$ Moreover, clinical studies using humanised anti-CD40L mAb have shown improvement in patients with autoimmune disorders, including lupus and immune thrombocytopenic purpura. ${ }^{20}$

In this study, we examined the effect of antiCD40L mAb against the development of cutaneous fibrosis and autoimmunity in TSK/+ mice.

\section{MATERIALS AND METHODS}

Mice and in vivo treatment

TSK/+ mice with a C57BL/6 genetic background were purchased from the Jackson Laboratory (Bar Harbor, ME, USA). To verify the TSK/+ genotype, polymerase chain reaction amplification of a partially duplicated fibrillin-1 gene was carried out using genomic DNA from each mouse as described. ${ }^{21}$ All studies were approved by the Committee on Animal Experimentation of Kanazawa University Graduate School of Medical Science. One-week-old TSK/+ mice were given either intraperitoneal $100 \mu \mathrm{g}$ of murine antiCD40L mAb (MR-1; BD PharMingen, San Diego, CA, USA) every week or the same amount of control mAb.

\section{Assessment of skin fibrosis}

The morphological characteristics of skin sections from 8-week-old female TSK/+ mice treated with anti-CD40L mAb were compared with those with 
control antibody under a light microscope. All skin sections were taken from the para-midline, upper back region as fullthickness sections. Tissues were fixed in 10\% formaldehyde solution for $24 \mathrm{~h}$, embedded in paraffin, and stained with haematoxylin and eosin. Dermal and hypodermal thickness was measured for multiple transverse perpendicular sections using an ocular micrometer. Ten random measurements were taken per section. To determine hydroxyproline content in the skin, $6 \mathrm{~mm}$ punch biopsies were treated with chloroform:methanol (2:1 vol:vol) and were analysed as described. ${ }^{11}$

\section{Flow cytometric analysis}

Single cell suspensions of lymphocytes from blood were used. Leucocytes $\left(0.5 \times 10^{6}\right.$ to $\left.1 \times 10^{6}\right)$ were stained at $4^{\circ} \mathrm{C}$ using predetermined optimal concentrations of antibodies for $20 \mathrm{~min}$. Cells with the forward and side light scatter properties of lymphocytes were analysed on a FACScan flow cytometer (BD Biosciences, San Diego, CA, USA).

\section{Enzyme-linked immunosorbent assay for detecting plasma sCD40L levels}

Specific enzyme-linked immunosorbent assay (ELISA) kits were used for measuring plasma sCD40L levels (Bender Medsystems, Vienna, Austria). Each sample was tested in duplicate.

\section{In vitro cutaneous fibroblast proliferation}

Trypsinised, third-passage fibroblasts $\left(2 \times 10^{4}\right.$ cells/well in $0.2 \mathrm{ml}$ ) were cultured in triplicate in 96-well plates with Dulbecco minimal Eagle's medium containing 10\% fetal calf serum with indicated concentration (see fig 4) of anti-CD40 antibody (1C10; R\&D Systems, Minneapolis, Minnesota, USA). Cellular proliferation was quantified by the addition of $10 \mathrm{mM}$ bromodeoxyuridine (Roche Diagnostics, Mannheim, Germany) during the last $18 \mathrm{~h}$ of a 2-day culture, and bromodeoxyuridine incorporation was assayed by ELISA (Roche Diagnostics).

\section{Determination of mRNA levels in cultured fibroblasts}

Total RNA was extracted from cultured fibroblasts and was reverse-transcribed into cDNA. Polymerase chain reaction was performed using the mouse COL1A2 primers and probe as described elsewhere. ${ }^{22}$ Optimal probe and primer concentrations were determined for each assay to ensure maximum specificity. Relative units were calculated by the comparative $\mathrm{C}_{\mathrm{T}}$ method.

\section{B cell proliferation}

Splenic B cells were purified by removing $\mathrm{T}$ cells with antiThy1.2 antibody-coated magnetic beads (Dynal, Inc., Lake Success, NY, USA). Purified B cells were cultured in $0.2 \mathrm{ml}$ of culture medium in 96-well flat-bottom plates with lipopolysaccharide (LPS; Sigma-Aldrich, St Louis, MO, USA), F $\left(a b^{\prime}\right)_{2}$ anti-mouse IgM antibodies (Cappel, Durham, NC, USA), or anti-CD40 $\mathrm{mAb}$ for $72 \mathrm{~h}$. Proliferation was assessed by the incorporation of $\left[{ }^{3} \mathrm{H}\right]$-labelled thymidine $(1 \mathrm{mCi} /$ well $)$ added during the last $16 \mathrm{~h}$, followed by scintillation counting. All treatments were carried out in triplicate cultures.

\section{Enzyme-linked immunosorbent assays for immunoglobulin and autoantibodies}

To determine immunoglobulin concentrations, ELISAs were carried out as described, ${ }^{11}$ using affinity-purified mouse IgM, IgG1, IgG2a, IgG2b, IgG3 and IgA (Southern Biotechnology Associates, Birmingham, Alabama, USA) to generate standard curves. Serum anti-topoisomerase (anti-topo) I autoantibody levels were determined with specific ELISA kits (Medical and Biological Laboratories, Nagoya, Japan) as described. ${ }^{11}$

\section{Statistical analysis}

The Mann-Whitney $U$ test was used for determining the level of significance of differences in sample means and Bonferroni's test was used for multiple comparisons.

\section{RESULTS}

Blockade of CD40/CD40L interactions by anti-CD40L monoclonal antibody attenuated the development of skin fibrosis in TSK/+ mice

One-week-old TSK/+ mice were given anti-CD40L mAb every week for seven weeks. Skin fibrosis in TSK/+ mice treated with anti-CD40L mAb was assessed by histopathology. The hypodermal thickness in TSK/+ mice was increased by ninefold compared with the wild-type littermates $(p<0.0001$, fig 1A,B). The TSK/+ mice treated with anti-CD40L mAb showed a markedly reduced hypodermal tissue, which was significantly $65 \%$ thinner than that found in TSK/+ mice $(p<0.001)$ but remained significantly thicker than that of wild-type littermates $(p<0.03)$. Anti-CD40L mAb administration in wild-type mice did not influence hypodermal thickness (data not shown). Cutaneous fibrosis was also assessed by quantifying the hydroxyproline content from skin samples (fig 1C). Hydroxyproline content in TSK/+ mice was increased by $24 \%$ relative to wild-type littermates $(p<0.0001)$. The anti-CD40L $\mathrm{mAb}$ treatment reduced hydroxyproline content by $17 \%$ in $\mathrm{TSK} /+$ mice compared with TSK/+ mice with the control antibody $(p<0.001)$. Anti-CD40L mAb administration did not affect the development of pulmonary emphysema and cardiac hypertrophy in TSK/+ mice (data not shown).

Next, 4-week-old TSK/+ mice were treated with anti-CD40L $\mathrm{mAb}$ weekly until 8 weeks old. This regimen did not show any effect against skin sclerosis: the hypodermal thickness of 8week-old TSK/+ mice that had been treated after they were 4 weeks old (0.38 (SD 0.05)) was similar to those with control antibody injection $(0.41(0.04))$. This regimen was designed around the observation that the difficulty to pinch up the back skin clearly appears at 4 weeks of age, although skin sclerosis in $\mathrm{TSK} /+$ mice is recognisable by 1 week after birth and develops fully by $\sim 2$ months of age. ${ }^{123}$ Thus, blockade of CD40/CD40L interactions attenuated the development of skin fibrosis in $\mathrm{TSK} /+$ mice.

\section{Blockade of CD40/CD40L interactions abrogated anti- topoisomerase I antibody production in TSK/+ mice}

Next, we examined anti-topo I antibody production in TSK/+ mice treated with anti-CD40L mAb. Pooled sera from 8-weekold TSK/+ mice had mean IgM and IgG anti-topo I antibody levels that were 2.3- and 1.7-fold higher than those found in wild-type littermates $(p<0.01$ and $p<0.005$, respectively; fig 2$)$. By contrast, anti-CD40L mAb significantly reduced the levels of IgM and IgG anti-topo I antibody in TSK/+ mice compared with TSK/+ mice with the control antibody treatment $(\mathrm{p}<0.05$ and $\mathrm{p}<0.01$, respectively; fig 2). Thus, anti-CD40L mAb normalised anti-topo I antibody production in $\mathrm{TSK} /+$ mice.

\section{CD40L expression by CD4 ${ }^{+} \mathrm{T}$ cells and plasma sCD40L levels were elevated in TSK/+ mice}

To determine whether the CD40/CD40L interactions were augmented in TSK/+ mice, first we determined CD40L 
Figure 1 Skin fibrosis in dorsal skin from wild-type littermates and tight-skin $(\mathrm{TSK} /+)$ mice treated with anti-CD40L mAb ( $\alpha$ CD40L) or control antibody (CTL). (A) Representative histological sections stained with haematoxylin and eosin $(\times 40)$. A triangle indicates the dermis, while double triangles show the subcutaneous loose connective tissue layer beneath the panniculus carnosus (arrow). Skin fibrosis was further assessed by quantitatively measuring hypodermal thickness (B) and skin hydroxyproline content (C). Horizontal bars represent mean hypodermal thickness (B) and mean hydroxyproline content (C). ${ }^{*} p<0.001$.
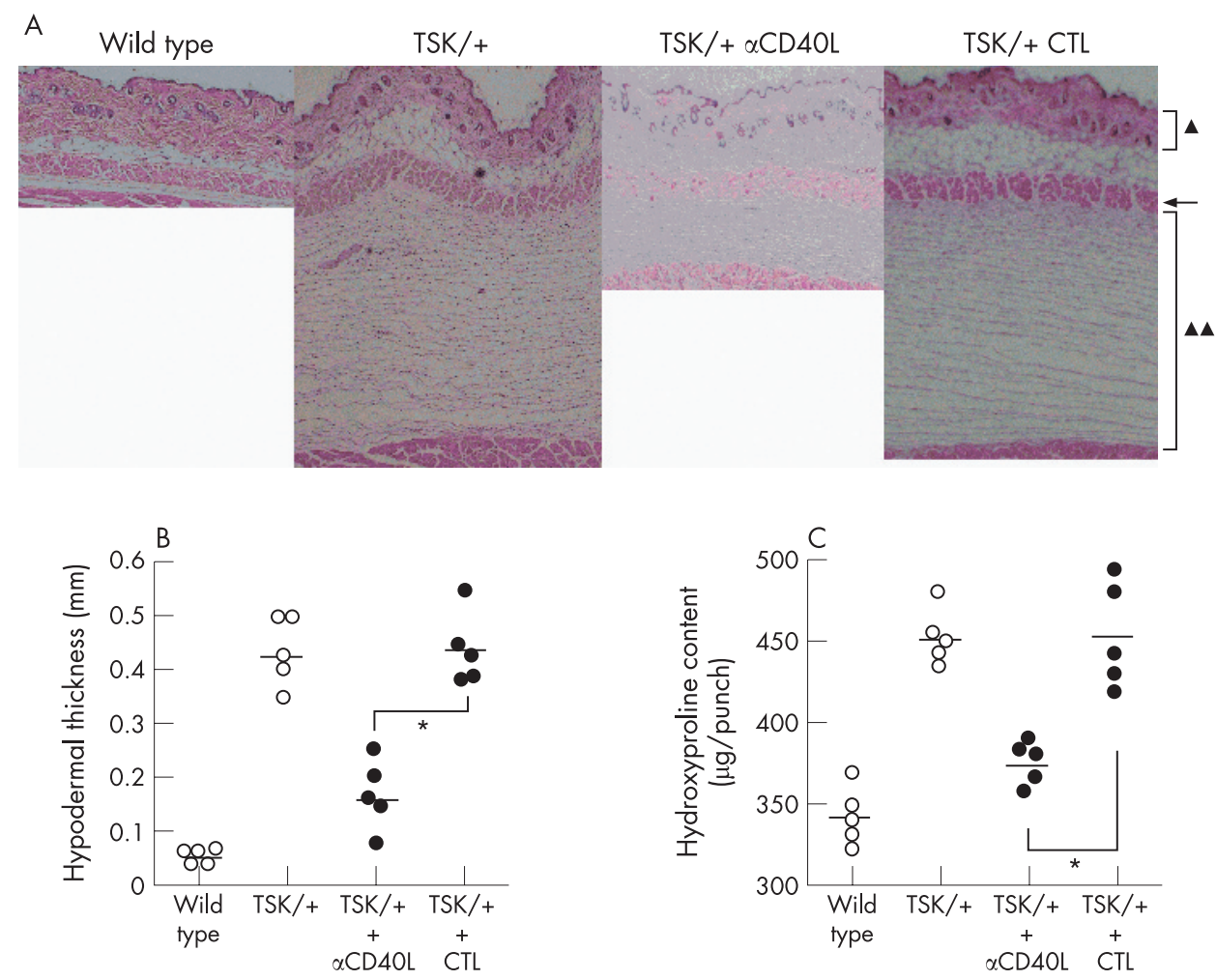

expression levels on $\mathrm{CD}^{+} \mathrm{T}$ cells from $\mathrm{TSK} /+$ mice. Because CD40L overexpression on $\mathrm{CD}^{+} \mathrm{T}$ cells indicates augmented CD40/CD40L interactions, as observed in several autoimmune diseases. ${ }^{24}$ Therefore, peripheral blood mononuclear cells from 4week-old TSK/+ or wild-type littermates were assessed by twocolour staining with flow cytometric analysis (fig 3A,B). Although $\mathrm{CD}^{+} \mathrm{T}$ cells from wild-type littermates rarely expressed CD40L, CD4 ${ }^{+} \mathrm{T}$ cells from TSK/+ mice had a 7.5fold increase in the percentage of $\mathrm{CD} 40 \mathrm{~L}^{+}$cells in comparison with wild-type littermates (4.4 (1.3)\% vs 0.53 (0.23)\%, p <0.001, fig 3A). However, $\mathrm{CD}^{+} \mathrm{T}$ cells from TSK/+ or wild-type littermates rarely expressed CD40L on their surface (fig 3B). Thus, $\mathrm{CD}^{+} \mathrm{T}$ cells from TSK/+ mice frequently hyperexpressed CD40L. Next, plasma levels of sCD40L in TSK/+ mice were examined, as $\mathrm{CD}_{40 \mathrm{~L}^{+}} \mathrm{T}$ cells may release $\mathrm{sCD} 40 \mathrm{~L}$. TSK/+ mice had an 11-fold increase in sCD40L compared with wild-type mice at 4 weeks of age $(p<0.0001)$, which was slightly decreased to a 7.7-fold increase at 8 weeks of age $(p<0.001$, fig 3C).

\section{Proliferative responses to CD40 signalling was augmented in TSK/+ fibroblasts}

To assess the association of fibroblast hyperplasia in TSK/+ mice with CD40/CD40L interactions, proliferative responses and the type I collagen $\alpha 2$ chain (COL1A2) mRNA levels of cultured fibroblasts were quantified. Proliferative responses and COL1A2 mRNA levels by anti-CD40 mAb stimulation $(10 \mathrm{mg} / \mu \mathrm{l})$ were significantly increased in TSK/+ fibroblasts compared with wild-type fibroblasts $(118 \%$ increase, $\mathrm{p}<0.001$ and $56 \%$ increase, $\mathrm{p}<0.03$, respectively; fig $4 \mathrm{~A}, \mathrm{~B})$. Thus, hyperresponsiveness to CD40/CD40L signalling was observed in TSK/+ fibroblasts.

\section{TSK/+ B cell hyperresponsiveness in association with CD40/ CD40L interactions}

As we have reported abnormalities of $\mathrm{B}$ cell responses in TSK/+ mice, ${ }^{1125}$ the association of CD40/CD40L interactions with $B$ cell hyperresponsiveness in TSK/+ mice was addressed. First, $\mathrm{TSK} /+\mathrm{B}$ cell proliferation to anti-IgM antibody, anti-CD40 $\mathrm{mAb}$ and LPS was assessed (fig 5A). Proliferation of B cells from
Figure 2 Serum anti-topoisomerase (topo) I antibody levels. Horizontal bars represent mean $\mathrm{OD}$ levels. Values in parentheses represent the dilutions of pooled sera giving half-maximal OD values in enzyme-linked immunosorbent assays, which was determined by linear regression analysis to generate arbitrary units per millilitre. ${ }^{*} \mathrm{p}<0.05$. ${ }^{*} \mathrm{p}<00.01$. CTL, control; TSK, tight-skin mice.
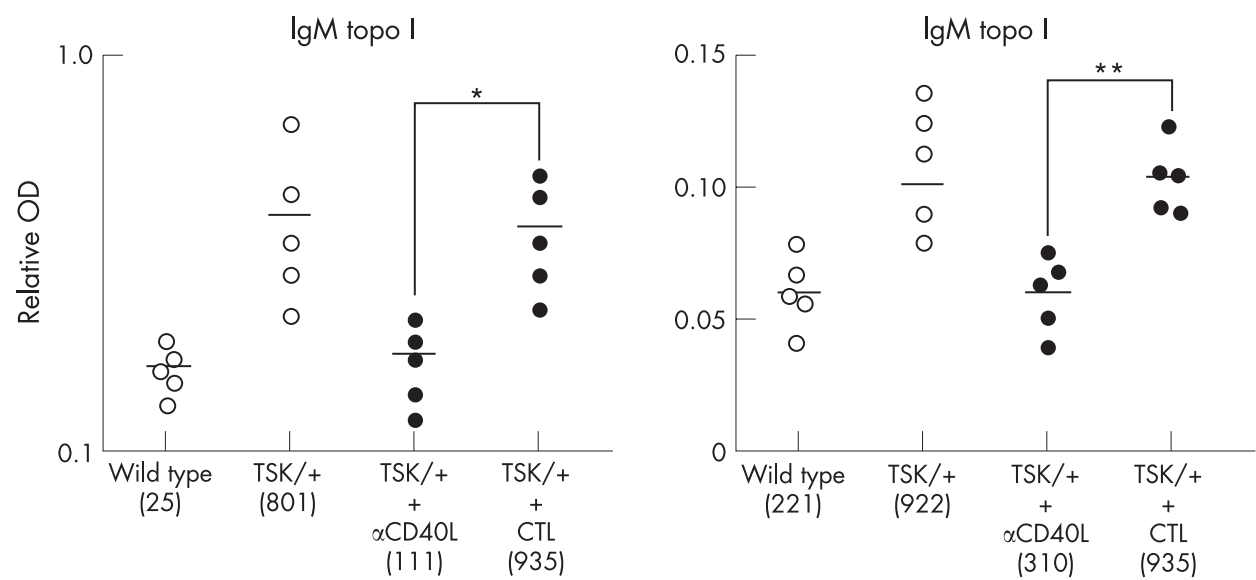

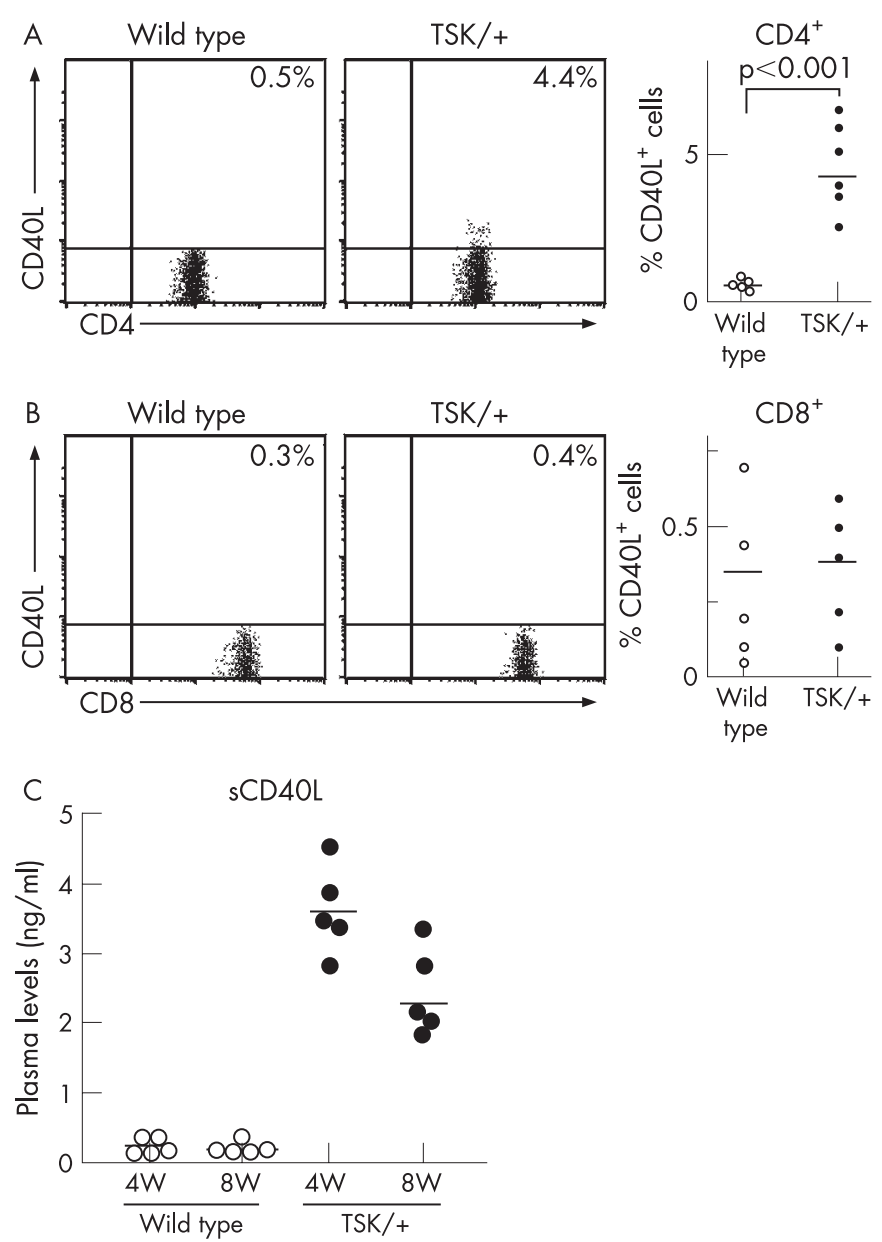

Figure 3 Two-colour immunofluorescence of $\mathrm{CD}^{+}(\mathrm{A})$ and $\mathrm{CD}^{+}(\mathrm{B}) \mathrm{T}$ cells for CD40L expression. Representative staining is shown. Based on background staining the dot-plots were divided into four quadrants. The percentages of positive cells were indicated in the quadrants and right panels. (C) Plasma levels of SCD40L were determined by enzyme-linked immunosorbent assay. Statistical analysis is provided in the Results section. TSK, tight-skin mice.

8-week-old TSK/+ to anti-IgM antibody and anti-CD40 mAb was significantly increased compared with wild-type B cells ( $22 \%$ increase $p<0.05$ and $53 \%$ increase $p<0.0001$, respectively), while proliferation to LPS was normal. Thus, augmented proliferation in TSK/+ B cells was relatively dependent on the signals through CD40/CD40L.
The effect of CD40/CD40L blocking in vivo on B cell responsiveness was assessed by determining serum immunoglobulin levels in TSK/+ mice (fig 5B). Eight-week-old TSK/+ mice had significantly elevated IgM $(\mathrm{p}<0.005), \operatorname{IgG1}(\mathrm{p}<0.01)$, IgG2a $(p<0.003)$ and IgG2b $(p<0.0003)$ levels compared with those of wild-type littermates, while IgG3 and IgA levels were not different from those of wild-type littermates. By contrast, 8week-old TSK/+ mice treated with anti-CD40L $\mathrm{mAb}$ had significantly decreased IgG1 $(p<0.0003), \operatorname{IgG} 2 a(p<0.005)$, $\operatorname{IgG2b}(p<0.0001)$ and IgA $(p<0.0001)$ levels compared with TSK/+ mice with control antibody treatment, while IgM levels were significantly higher than those of TSK/+ mice with control antibody $(p<0.001)$. Thus, TSK/+ mice exhibited hyper- $\gamma$ globulinaemia that was associated with CD40/CD40L interactions.

\section{DISCUSSION}

In the current study, anti-CD40L mAb therapy showed remarkable effectiveness in $\mathrm{TSK} /+$ mice even compared with our previous report of anti-CD20 mAb therapy, ${ }^{26}$ suggesting that CD40/CD40L interactions are critical for the development of skin fibrosis in TSK/+ mice. While dermal thickness is similar between TSK/+ mice and wild-type littermates, the hypodermal thickness is significantly increased in TSK/+ mice relative to wild-type littermates (fig 1A,B). Treatment by anti-CD40L mAb markedly reduced progression of hypodermal thickening in TSK/+ mice (fig 1A,B), although the treatment did not affect skin fibrosis in TSK/+ mice with established disease. As antiCD40L mAb affected neither hypodermal thickness of wild-type mice nor dermal thickness of TSK/+ mice (fig 1A), anti-CD40L $\mathrm{mAb}$ treatment specifically inhibited the abnormal development of hypodermal fibrosis in TSK/+ mice. Furthermore, anti-CD40L $\mathrm{mAb}$ treatment normalised abnormal anti-topo I antibody production and hyper- $\gamma$-globulinaemia in TSK/+ mice (figs 2 and 5). Thus, anti-CD40L mAb therapy effectively attenuated the abnormal development of skin fibrosis and $\mathrm{B}$ cell activation in $\mathrm{TSK} /+$ mice.

Although causal association between abnormal B cell activation and hypodermal hyperplasia in TSK/+ mice remains unknown in this study, some evidence has suggested the association. Adoptive transfer of both $\mathrm{T}$ and $\mathrm{B}$ cells from TSK/+ mice induces cutaneous collagen deposition and autoantibody production in wild-type mice, while the infusion of purified $\mathrm{T}$ cells alone does not lead to the development of TSK syndrome. ${ }^{6}$ Deficiency of CD19 as well as B cell depletion using anti-CD20 $\mathrm{mAb}$ result in markedly reduced skin fibrosis in TSK/+ mice. ${ }^{1126}$ Furthermore, the development of skin fibrosis correlated closely
Figure 4 (A) Fibroblast proliferative response to anti-CD40 monoclonal antibody (mAb). Fibroblasts were cultured with the indicated amounts of anti-CD40 mAb. Values represent the mean OD (SEM) of bromodeoxyuridine concentration. These results represent those obtained in four independent experiments. (B) mRNA levels of the type I collagen $\alpha 2$ chain (COL1A2) in the cultured fibroblast. ${ }^{*} p<0.05 ;{ }^{* *} p<0.001$. TSK, tight-skin mice.
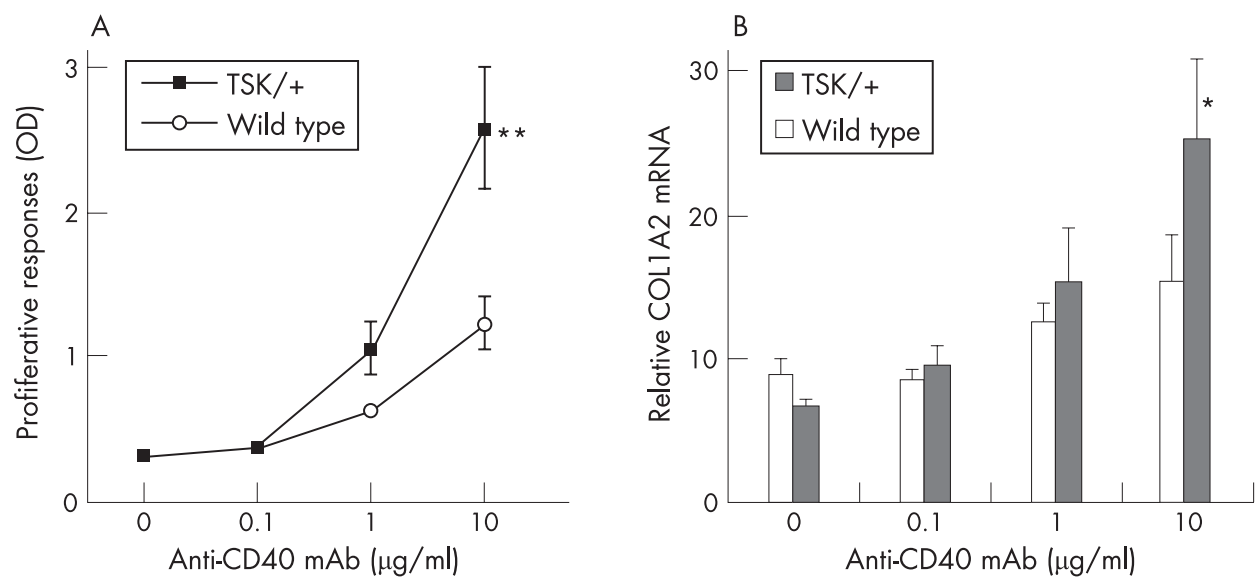

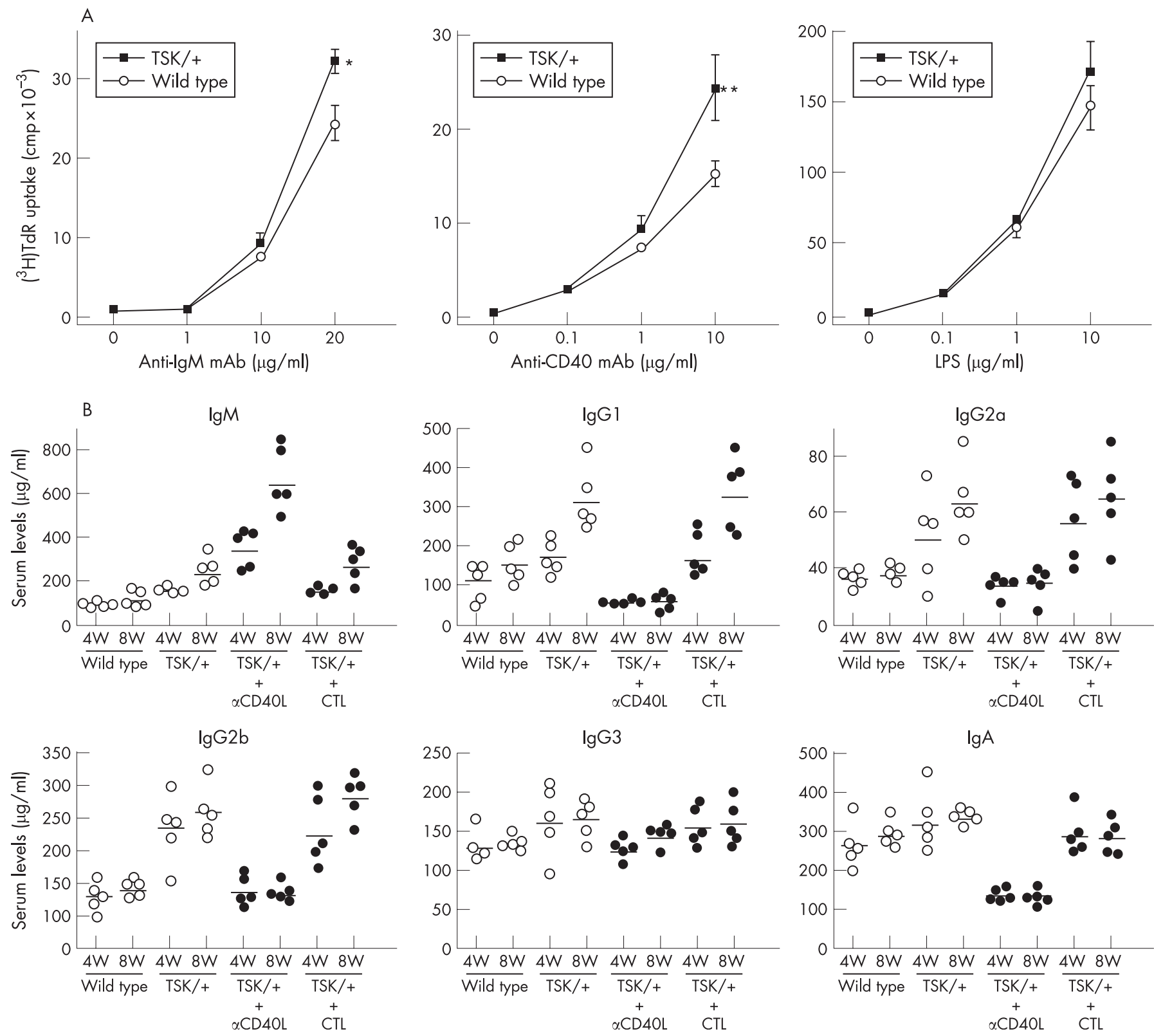

Figure 5 (A) B cell proliferation in response to anti-IgM antibody, anti-CD40 monoclonal antibody (mAb), or lipopolysaccharide (LPS). Values represent the mean $\mathrm{cpm}(\mathrm{SEM})$ of labelled thymidine. These results represent those obtained in four independent experiments. ${ }^{*} p<0.05 ;{ }^{*} p<0.001$. (B) Serum immunoglobulin levels. Pooled sera from 4-week-old and 8-week-old tight-skin (TSK/+) mice were used to determine immunoglobulin levels by isotype-specific enzyme-linked immunosorbent assays. Statistical analysis is provided in the Results section. CTL, control.

with serum anti-topo I antibody levels in TSK/+ mice. ${ }^{27}$ The current study suggested that both augmented B cell and fibroblast response to CD40 signal influence the phenotype of $\mathrm{TSK} /+$ mice.

As CD40 is expressed on various cell types, there are several potential mechanisms for the effectiveness of anti-CD40L mAb therapy in TSK/+ mice. First, ligation of CD40L to CD40 expressed by fibroblasts is likely to facilitate fibroblast proliferation. ${ }^{17} 2829$ Proliferative response to CD40 signalling was significantly augmented in TSK/+ fibroblasts (fig 4A,B). The source of CD40L ligation remains unclear, as very little $\mathrm{T}$ cell infiltration in the cutaneous and subcutaneous tissue was observed in TSK/+ mice (fig 1A). TSK/+ mice had a marked increase in plasma sCD40L compared with wild-type littermates by 11 -fold at 4 weeks of age and by 7.7 -fold at 8 weeks, respectively (fig $3 \mathrm{C}$ ). Therefore, increased sCD40L may lead to hyperactivation of fibroblasts in TSK/+ mice.

Consistent with the positive results in this study of antiCD40L $\mathrm{mAb}$ in TSK/+ mice, critical roles of CD40/CD40L interactions have also been suggested in other animal autoimmune models. ${ }^{18} 19$ Moreover, clinical studies using humanised anti-CD40L mAb show improvement in patients with autoimmune disorders, including lupus, immune thrombocytopenic purpura and psoriasis. $^{20}$ In SSc, blockade of CD40/CD40L interaction has inhibited anti-topo I antibody production in cultured $\mathrm{T}$ and $\mathrm{B}$ cells from patients with SSc with anti-topo I antibody. ${ }^{30}$ Serum and plasma levels of SCD40L, which activates CD40/CD40L interactions, are markedly elevated and correlated with the disease severity. ${ }^{31}{ }^{32}$ CD40 expression in skin fibroblasts, circulating soluble CD40 levels, and CD40L expression on 
$\mathrm{CD}^{+} \mathrm{T}$ cells from patients with SSc is increased. ${ }^{24}{ }^{33}{ }^{34}$ Thus, CD40/CD40L interactions play important roles in the development of autoimmune disorders, including SSc. In conclusion, the present study suggests that CD40/CD40L interactions may be possible targets in the therapy of SSc, although no therapy has been proven effective in suppressing or improving skin sclerosis in controlled studies.

Acknowledgements: We thank Ms M Matsubara, Y Yamada, A Usui and M Yozaki for technical assistance. This work is supported by a Grant-in-Aid from the Ministry of Education, Science, Culture of Japan and a grant from Shiseido.

\section{Competing interests: None.}

\section{REFERENCES}

1. Green MC, Sweet HO, Bunker LE. Tight-skin, a new mutation of the mouse causing excessive growth of connective tissue and skeleton. Am J Pathol 1976;82:493-512.

2. Bona C, Rothfield N. Autoantibodies in scleroderma and tightskin mice. Curr Opin Immunol 1994:6:931-7.

3. Murai C, Saito S, Kasturi KN, Bona CA. Spontaneous occurrence of anti-fibrillin-1 autoantibodies in tight-skin mice. Autoimmunity 1998;28:151-5.

4. Tan FK, Arnett FC, Antohi S, Saito S, Mirarchi A, Spiera H, et al. Autoantibodies to the extracellular matrix microfibrillar protein, fibrillin-1, in patients with scleroderma and other connective tissue diseases. J Immunol 1999;163:1066-72.

5. Gayraud B, Keene DR, Sakai LY, Ramirez F. New insights into the assembly of extracellular microfibrils from the analysis of the fibrillin 1 mutation in the tight skin mouse. J Cell Biol 2000;150:667-80.

6. Phelps RG, Daian C, Shibata S, Fleischmajer R, Bona CA. Induction of skin fibrosis and autoantibodies by infusion of immunocompetent cells from tight skin mice into C57BL/6 Pa/Pa mice. J Autoimmun 1993;6:701-18.

7. Walker MA, Harley RA, DeLustro FA, LeRoy EC. Adoptive transfer of tsk skin fibrosis to $+/+$ recipients by tsk bone marrow and spleen cells. Proc Soc Exp Biol Med 1989;192:196-200.

8. Ong CJ, Ip S, Teh SJ, Wong C, Jirik FR, Grusby MJ, et al. A role for Thelper 2 cells in mediating skin fibrosis in tight-skin mice. Cell Immunol 1999;196:60-8.

9. McGaha T, Saito S, Phelps RG, Gordon R, Noben-Trauth N, Paul WE, et al. Lack of skin fibrosis in tight skin (TSK) mice with targeted mutation in the interleukin-4ralpha and transforming growth factor-beta genes. J Invest Dermatol 2001;116:136-43.

10. Kodera T, McGaha TL, Phelps R, Paul WE, Bona CA. Disrupting the IL-4 gene rescues mice homozygous for the tight-skin mutation from embryonic death and diminishes TGF-beta production by fibroblasts. Proc Natl Acad Sci USA 2002;99:3800-5.

11. Saito E, Fujimoto M, Hasegawa M, Komura K, Hamaguchi Y, Kaburagi Y, et al. CD19dependent $\mathrm{B}$ lymphocyte signaling thresholds influence skin fibrosis and autoimmunity in the tight-skin mouse. J Clin Invest 2002;109:1453-62.

12. Ong C, Wong C, Roberts CR, Teh HS, Jirik FR. Anti-IL-4 treatment prevents dermal collagen deposition in the tight-skin mouse model of scleroderma. Eur $\mathrm{J}$ Immunol 1998;28:2619-29.

13. Tsuji-Yamada J, Nakazawa M, Takahashi K, lijima K, Hattori S, Okuda K, et al. Effect of IL-12 encoding plasmid administration on tight-skin mouse. Biochem Biophys Res Commun 2001;280:707-12.

14. Quezada SA, Jarvinen LZ, Lind EF, Noelle RJ. CD40/CD154 interactions at the interface of tolerance and immunity. Annu Rev Immunol 2004;22:307-28.
15. Kato K, Santana-Sahagun E, Rassenti LZ, Weisman MH, Tamura N, Kobayashi S, et al. The soluble CD40 ligand SCD154 in systemic lupus erythematosus. J Clin Invest 1999; 104:947-55.

16. Karmann K, Hughes CC, Schechner J, Fanslow WC, Pober JS. CD40 on human endothelial cells: inducibility by cytokines and functional regulation of adhesion molecule expression. Proc Natl Acad Sci USA 1995;92:4342-6.

17. Fries KM, Sempowski GD, Gaspari AA, Blieden T, Looney RJ, Phipps RP. CD40 expression by human fibroblasts. Clin Immunol Immunopathol 1995;77:42-51.

18. Burkly LC. CD40 pathway blockade as an approach to immunotherapy. Adv Exp Med Biol 2001;489:135-52.

19. Vogel LA, Noelle RJ. CD40 and its crucial role as a member of the TNFR family. Semin Immunol 1998;10:435-42.

20. Sidiropoulos PI, Boumpas DT. Lessons learned from anti-CD40L treatment in systemic lupus erythematosus patients. Lupus 2004;13:391-7.

21. Denton CP, Zheng B, Shiwen X, Zhang Z, Bou-Gharios G, Eberspaecher H, et al. Activation of a fibroblast-specific enhancer of the proalpha2(I) collagen gene in tightskin mice. Arthritis Rheum 2001;44:712-22.

22. Chujo S, Shirasaki F, Kawara S, Inagaki Y, Kinbara T, Inaoki M, et al. Connective tissue growth factor causes persistent proalpha2 (I) collagen gene expression induced by transforming growth factor-beta in a mouse fibrosis model. $J$ Cell Physiol 2005;203:447-56.

23. Dodig TD, Mack KT, Cassarino DF, Clark SH. Development of the tight-skin phenotype in immune-deficient mice. Arthritis Rheum 2001;44:723-7.

24. Valentini G, Romano MF, Naclerio C, Bisogni R, Lamberti A, Turco MC, et al. Increased expression of CD40 ligand in activated CD4+ T lymphocytes of systemic sclerosis patients. J Autoimmun 2000;15:61-6.

25. Asano N, Fujimoto M, Yazawa N, Shirasawa S, Hasegawa M, Okochi H, et al. B Lymphocyte signaling established by the CD19/CD22 loop regulates autoimmunity in the tight-skin mouse. Am J Pathol 2004;165:641-50.

26. Hasegawa M, Hamaguchi Y, Yanaba K, Bouaziz JD, Uchida J, Fujimoto M, et al. Blymphocyte depletion reduces skin fibrosis and autoimmunity in the tight-skin mouse model for systemic sclerosis. Am J Pathol 2006;169:954-66.

27. Hatakeyama A, Kasturi KN, Wolf I, Phelps RG, Bona CA. Correlation between the concentration of serum anti-topoisomerase I autoantibodies and histological and biochemical alterations in the skin of tight skin mice. Cell Immunol 1996;167:135-40.

28. Kaufman J, Sime PJ, and Phipps RP. Expression of CD154 (CD40 ligand) by human lung fibroblasts: differential regulation by IFN-gamma and IL-13, and implications for fibrosis. J Immunol 2004;172:1862-71.

29. Atamas SP, Luzina IG, Dai H, Wilt SG, White B. Synergy between CD40 ligation and IL-4 on fibroblast proliferation involves IL-4 receptor signaling. J Immunol 2002;168:1139-45.

30. Kuwana M, Medsger TA Jr, Wright TM. T and B cell collaboration is essential for the autoantibody response to DNA topoisomerase I in systemic sclerosis. J Immunol 1995; 155:2703-14.

31. Komura K, Sato S, Hasegawa M, Fujimoto M, Takehara K. Elevated circulating CD40L concentrations in patients with systemic sclerosis. J Rheumatol 2004;31:514-19.

32. Allanore Y, Borderie D, Meune C, Lemarechal H, Weber S, Ekindjian OG, et al. Increased plasma soluble CD40 ligand concentrations in systemic sclerosis and association with pulmonary arterial hypertension and digital ulcers. Ann Rheum Dis 2005;64:481-3.

33. Fukasawa C, Kawaguchi Y, Harigai M, Sugiura T, Takagi K, Kawamoto M, et al. Increased CD40 expression in skin fibroblasts from patients with systemic sclerosis (SSc): role of CD40-CD154 in the phenotype of SSc fibroblasts. Eur J Immunol 2003;33:2792-800.

34. Komura K, Fujimoto M, Matsushita T, Yanaba K, Kodera M, Kawasuji A, et al. Increased serum soluble CD40 levels in patients with systemic sclerosis. J Rheumatol 2007;34:353-8. 